\title{
From the top-down: Transformational leadership considerations for health care organizations
}

\author{
Ericka Sanner-Stiehr*1, Clair Reynolds Kueny ${ }^{2}$ \\ ${ }^{1}$ College of Nursing, University of Missouri - St. Louis, St. Louis, Missouri, United States \\ ${ }^{2}$ Department of Psychological Science, University of Missouri - Rolla, Rolla, Missouri, United States
}

Received: April 27, 2017

Accepted: May 26, 2017

Online Published: June 5, 2017

DOI: $10.5430 /$ jha.v6n4p1

URL: https://doi.org/10.5430/jha.v6n4p1

\begin{abstract}
Nurse leaders can positively influence critical issues in healthcare by engaging in transformational leadership (TL) practices. High in humility, extraversion, self-efficacy, and emotional intelligence, transformational leaders focus on followers as individuals and inspire high goal attainment. Organizations can increase TL behaviors through top-down training strategies. This paper evaluates salient TL characteristics and considerations for organizations wishing to create positive organization-wide change.
\end{abstract}

Key Words: Transformational leadership, Healthcare, Training, Individual characteristics, Organizational culture

\section{INTRODUCTION}

Nurse leaders are in a position to positively influence critical issues in nursing and health care. Each year, as many as $17 \%$ of Registered Nurses (RNs) providing direct patient care leave their jobs. ${ }^{[1]}$ This considerably high turnover rate negatively impacts institutions, patients, and other nurses and staff working in units or departments where turnover rates are high. Health care institutions spend between $\$ 5.2 \mathrm{M}$ - $\$ 8.1 \mathrm{M}$ annually to replace RNs who leave, ${ }^{[1]}$ creating added financial burdens in an already strained economic climate. Turnover can result in a loss of invaluable clinical nursing expertise when experienced nurses leave, whose expertise is crucial in mentoring novice nurses entering the profession and delivering high quality patient care. Patient outcomes can be further negatively impacted by interruptions to daily operations due to understaffing. These extensive sequelae of nursing turnover create compelling motivation for health care institutions to actively seek ways to increase nurse retention.
Job satisfaction is a consistent and strong predictor of nursing staff retention. Level of autonomy, quality of workplace relationships, ${ }^{[2]}$ level of supervisory support, adequacy of resources needed to perform one's job, ${ }^{[3]}$ feelings of empowerment, ${ }^{[4,5]}$ and organizational structure ${ }^{[2,3]}$ strongly influence job satisfaction and, ultimately, retention. Additionally, workload, opportunities for professional challenges, feelings of being valued for contributions, and collegiality in the workplace are associated with job satisfaction among RNs of multiple experience levels. ${ }^{[6,7]}$ Nurse leaders occupy a pivotal position, able to influence many of these main elements of job satisfaction. Thus, leadership style can ultimately influence staff retention rates, potentially saving institutions millions of dollars annually by avoiding unnecessary staff turnover.

\section{Transformational leadership (TL)}

The TL model is characterized by an integration of four key dimensions that shift followers' beliefs, values, and attitudes through individual, personal attention: Individualized Con-

\footnotetext{
* Correspondence: Ericka Sanner-Stiehr; Email: sannerstiehre@umsl.edu; Address: College of Nursing, University of Missouri - St. Louis, St. Louis, Missouri, United States.
} 
sideration, Intellectual Stimulation, Inspirational Motivation, and Idealized Influence. The fundamental feature of TL that distinguishes it from other leadership styles is its focus on cultivating individual relationships with followers. TL is also a moderate-strong predictor of job performance, helping behaviors, employee engagement, organizational commitment, trust in and satisfaction with supervisors, perceptions of leader effectiveness in achieving results, and followers' extra effort. ${ }^{[8,9]}$

TL can positively impact RN job satisfaction and the institutions that employ them by impacting how RNs experience their work and their workplace. ${ }^{[10,11]}$ Employee job satisfaction is linked to the mentoring, shared vision, and generosity manifested in enhanced leader-follower relationships of the TL model. ${ }^{[12]}$ High in emotional intelligence, transformational leaders are able to reframe negative thoughts into positive $^{[13]}$ and motivate followers, leveraging unique individual talents $^{[14]}$ for maximum team effectiveness. TL cultivates feelings of empowerment and confidence, ${ }^{[15]}$ decreases stress levels, ${ }^{[16]}$ and increases follower emotional wellness. Unsurprisingly, these positive changes in the workplace can improve employee health outcomes, ${ }^{[17]}$ decrease burnout ${ }^{[18]}$ and increase both intent to stay in a position, ${ }^{[19,20]}$ and actual retention rates. ${ }^{[18]}$

In nursing and health care, employee engagement and team cohesion are crucial for patient outcomes. TL can increase nurse innovation, ${ }^{[21]}$ improve patient satisfaction, and decrease mortality, medication errors, use of restraints, and incidence of hospital acquired infections. ${ }^{[22]}$ Furthermore, the culture of trust created by TL in health care settings can increase employees' comfort in reporting wrongdoings and negative events ${ }^{[23]}$ and frequency of safety event reporting ${ }^{[24]}$ without fear of retaliation and punishment. ${ }^{[23]}$

Follower outcomes are positively impacted by TL leadership when compared to transactional and laissez-faire styles. ${ }^{[9]}$ These traditional leadership styles lack the personalized attention that is fundamental to TL. In contrast to the individualized approach of TL which motivates through personal connection, transactional leadership focuses on the economic exchange between leader and individual team members. ${ }^{[9]}$ This contingent-reward approach offers followers something of value such as financial compensation in exchange for the desired behaviors. In sharp contrast to both TL and transactional leadership, laissez-faire leadership can be described as the absence of leadership. ${ }^{[25]}$ In this model, leaders avoid having to make decisions, rarely take action, and are absent when team-members need them. ${ }^{[9]}$

TL was a significantly stronger predictor of followers' satisfaction with their leaders and beliefs of leader effectiveness when compared to transactional leadership. Furthermore, when controlling for all leadership-styles in regression analyses, TL was the strongest predictor of overall follower outcomes, including follower satisfaction with leader, follower motivation, and leader effectiveness. Finally, compared to transactional leadership, TL was the more stable, reliable form of leadership across professions including college, military, and public-sector settings at both supervisory and mid or upper levels of leadership.

These findings carry heavy implications for healthcare organizations focused on improving outcomes by increasing TL among management and administration. In this paper, we present a detailed deconstruction of personal characteristics associated with TL. Furthermore, we discuss training considerations and organizational influences that can impact the level of TL behaviors among leadership.

\section{TL: KEY DIMENSIONS}

A literature search was conducted in both organizational psychology (Business Source Premier, PsycInfo, and PsycArticles) and healthcare research databases (Business Source Premier, PsycInfo, PsycArticles, Academic Search Complete, CINAHL, PubMed, and Medline). Boolean and truncation search techniques were used to maximize search return. Key terms included: antecedent, predictor, transformational leader, leader, leadership, nursing, healthcare, hospital, administration, training, and staff retention.

\subsection{Individualized consideration}

Transformational leaders demonstrate concern for individuals, get to know them, listen to employee concerns and ideas, determine assignments based on individual strengths and desires, and promote individual success and achievement. ${ }^{[25]}$ These leaders may be described as demonstrating "caring" behaviors about team members. ${ }^{[26]}$ Leaders who lead through individualized consideration attend to each follower's unique needs and mentor the follower through consideration of their unique concerns. ${ }^{[9]}$ Transformational leaders actively listen and fully engage the person and issue at hand. This enables transformational leaders to hear team members' ideas and identify their strengths, maximizing their skill sets and achieving group outcomes. Getting to know team members as individuals with personal goals and feelings allows transformational leaders to provide members with development opportunities and creates a culture of caring among the team.

\subsection{Intellectual stimulation}

Transformational leaders promote team members' abilities to think through problems and create solutions rather than telling them what to do, encourage them to reexamine as- 
sumptions and approach situations creatively, and guide team members to carefully think through outcomes associated with courses of action. That is, by taking an intellectual stimulation approach to leading, transformational leaders boost innovation and achievement by challenging assumptions and encouraging additional input from their followers. ${ }^{\text {[9] }}$

\subsection{Inspirational motivation}

Transformational leaders motivate team members to excellence through optimism, creating an attainable view of the future and goal achievement. They create a sense of priority and purpose for the group, are passionate about the group's mission, ${ }^{[26]}$ and are able to communicate that vision and mission articulately, dispelling ambiguities that can undermine morale and performance. ${ }^{[27]}$ Leaders who lead through inspirational motivation inspire followers by providing meaning and purpose to the current goals, and by creating an attractive path toward achieving a goal. ${ }^{[25]}$ Transformational leaders display passion for the team's goals and present even lofty goals as attainable, which can result in members exceeding their own expectations.

\subsection{Idealized influence}

This dimension describes leaders' behavior as drawing in followers through emotions and admiration ${ }^{[9]}$ and engendering trust and confidence from team members. ${ }^{[27]}$ This is partially accomplished through role-modeling integrity, trust, honesty, and purpose. Transformational leaders display a high level of competence in their positions and are accountable for their own work and work that is delegated to team members. ${ }^{[25]}$ Delegating work to team members can create a sense of empowerment and trust. Ongoing self-reflection results in transformational leaders who are accountable, authentic, and willing to be vulnerable, demonstrating a well-defined sense of self.

\section{INCREASING TL}

Individual characteristics are predictors of TL including extraversion, agreeableness, humility, self-efficacy, and Emotional Intelligence. Articles for the literature review were included in this section if they empirically tested predictors and antecedents of TL. We summarize findings of these characteristics as they relate to TL below as well as in Table 1. Additionally, we provide recommendations for organizations to leverage these individual differences to increase TL within their units (see Table 1).

\subsection{Individual characteristics Personality traits}

Meta-analytic findings indicate that high extraversion, characterized by energy and enthusiasm, and low neuroticism, characterized by low anxiety and high emotional stability, ${ }^{[28]}$ were significant, weak-moderate predictors of Intellectual Stimulation, Idealized Influence, and Inspirational Motivation, and an overall combination of all four TL dimensions. ${ }^{[28,29]}$ Extraversion was also a moderate predictor of Individualized Consideration. ${ }^{[29]}$ These relationships were even stronger after controlling for transactional leader dimensions, with Idealized Influence having the strongest relationships with these personality traits, providing clear support for extraversion as a significant predictor of TL behaviors. Furthermore, positive affect which is highly related to extraversion, and agreeableness, which is characterized as being cooperative, warm, and friendly, ${ }^{[28]}$ are both positive predictors of TL. ${ }^{[30]}$

\subsection{Humility}

Humility,a distinct personality trait characterized as being sincere and modest, ${ }^{[28]}$ is theorized to be a significant predictor of Idealized Influence. The tendency for self-reflection and the emphasis on how one works with others that are characteristic of the humility trait should be directly related to leaders' efforts to better understand their own identities through self-reflection and to clearly define their role within the leader-follower relationships. ${ }^{[31]}$ However, the specific relationship between humility and Idealized Influence leader behaviors has yet to be tested. Notably, some research has found that self-reflection helps leaders to define their own personal mission statement and set personal goals that can be clearly articulated to team members. As a result, transformational leaders are stable and grounded, lending a sense of assurance to their team (p. 30). ${ }^{[27]}$

\subsection{Self-efficacy}

Self-efficacy, or confidence in one's abilities, is also positively linked to TL. ${ }^{[32,33]}$ Influenced by motivation, affect, cognitions, and successful previous engagement in a behavior, ${ }^{[34]}$ these qualities of self-efficacy instill confidence and can positively influence team member affect and motivation. Relatedly, leaders' core self-evaluations (CSE), a combination of emotional stability, locus of control, self-efficacy, and self-esteem, are positively linked to both overall TL perceptions, as well as each specific dimension of TL. ${ }^{[35]}$ These findings corroborate the preceding research discussed in this paper discussing the positive relationship between leader selfefficacy and TL as well as the negative relationship between neuroticism (the opposite of emotional stability) and TL. Thus, it is not surprising that a leader's core self-evaluation also predicts their level of TL. 


\subsection{Emotional intelligence}

Emotional intelligence, described as the ability to understand emotions from others' point of view as well as one's own emotions $^{[36]}$ is strongly linked to TL behaviors. ${ }^{[30,37]}$ Leaders skilled at perceiving and understanding a situation from another's point of view are also more likely to be rated by followers as transformational in leadership style. ${ }^{[38]}$ Emo- tional intelligence further requires using an understanding of others' emotions effectively and appropriately. ${ }^{[36]}$ Research on emotional intelligence and TL suggests that emotional intelligence abilities are significantly, moderately related to each dimension of TL. ${ }^{[37]}$ Furthermore, an interaction effect between emotion recognition and extraversion significantly increases TL leadership than either trait alone. ${ }^{[30]}$

Table 1. Individual and organizational predictors of TL and related recommendations

\begin{tabular}{|c|c|c|}
\hline Individual Differences & Impact on TL & Recommendations \\
\hline \multicolumn{3}{|l|}{ Personality Traits } \\
\hline - Extraversion & $\begin{array}{l}\text { - Positively related to TL; leaders who are energetic } \\
\& \text { enthusiastic are more likely to display TL } \\
\text { behaviors }\end{array}$ & $\begin{array}{l}\text { - Consider these traits when hiring for a } \\
\text { leadership position or promoting someone } \\
\text { into a leadership position. }\end{array}$ \\
\hline - Neuroticism & $\begin{array}{l}\text { - Negatively related to TL: leaders who are anxious } \\
\text { and have frequent mood swings are less likely to } \\
\text { display TL behaviors }\end{array}$ & \\
\hline - Agreeableness & $\begin{array}{l}\text { Positively related to TL: leaders who are friendly, } \\
\text { trusting, and cooperative are more likely to display } \\
\text { TL behaviors }\end{array}$ & \\
\hline - Humility & $\begin{array}{l}\text { - Positively related to TL (theorized): leaders who are } \\
\text { sincere and modest are more likely to display TL } \\
\text { behaviors }\end{array}$ & \\
\hline \multicolumn{3}{|l|}{ Self-efficacy \& CSE } \\
\hline - Self-efficacy & $\begin{array}{l}\text { Positively related to TL; leaders who are more } \\
\text { confident in their abilities are more likely to display } \\
\text { TL behaviors }\end{array}$ & $\begin{array}{l}\text { Monitor \& manage leaders' self-efficacy; } \\
\text { increase self-efficacy through training }\end{array}$ \\
\hline - Core self-evaluations & $\begin{array}{l}\text { Positively related to TL; leaders who are confident } \\
\text { in their abilities, have positive opinion of } \\
\text { themselves, are high in emotional stability, and } \\
\text { believe they have control over events are more } \\
\text { likely to display TL }\end{array}$ & $\begin{array}{l}\text { - Consider CSE when hiring or promoting. } \\
\text { Possible to improve through training as } \\
\text { well. }\end{array}$ \\
\hline \multicolumn{3}{|l|}{ Interpersonal Skills \& Abilities } \\
\hline - Perspective-taking & $\begin{array}{l}\text { - Positively related to TL; leaders who can accurately } \\
\text { perceive and understand a situation from others' } \\
\text { points of view are more likely to display TL }\end{array}$ & $\begin{array}{l}\text { Monitor \& manage leaders' } \\
\text { perspective-taking; increase } \\
\text { perspective-taking through training }\end{array}$ \\
\hline - Emotional intelligence & $\begin{array}{l}\text { Positively related to TL; leaders who accurately } \\
\text { interpret emotions and use the information to make } \\
\text { effective decisions are more likely to display TL }\end{array}$ & $\begin{array}{l}\text { Consider EI when hiring or promoting. } \\
\text { Possible to improve through training as } \\
\text { well. }\end{array}$ \\
\hline - Organizational Characteristics & - Impact on TL & - Recommendations \\
\hline \multicolumn{3}{|l|}{ Workplace Relationships } \\
\hline - Bottom-up/Top-down & $\begin{array}{l}\text { Positively related to TL; leaders who have positive } \\
\text { relationships and open communication with both } \\
\text { their leaders (top-down) as well as their } \\
\text { subordinates (bottom-up) are more likely to display } \\
\text { TL }\end{array}$ & $\begin{array}{l}\text { Maintain open communication through all } \\
\text { channels in the organization; establish a } \\
\text { positive rapport at all levels }\end{array}$ \\
\hline - Collective identity & $\begin{array}{l}\text { Positively related to TL; leaders whose } \\
\text { self-definitions are defined by the unit they belong } \\
\text { to are more likely to display TL }\end{array}$ & $\begin{array}{l}\text { - Help leaders recognize their contributions } \\
\text { to the organization and what the } \\
\text { organization does for them as a way to } \\
\text { show how the unit contributes to their } \\
\text { self-definition }\end{array}$ \\
\hline \multicolumn{3}{|l|}{ Organizational Demands } \\
\hline - Demands-abilities fit & $\begin{array}{l}\text { - Positively related to TL; leaders whose abilities are } \\
\text { appropriately matched to the demands of the } \\
\text { position are more likely to display TL }\end{array}$ & $\begin{array}{l}\text { Know the abilities necessary for the job } \\
\text { (i.e., abilities necessary to meet the } \\
\text { demands), then consider these abilities } \\
\text { when hiring or promoting }\end{array}$ \\
\hline - Developmental challenges & $\begin{array}{l}\text { (Usually) Positively related to TL; if developmental } \\
\text { challenges are energizing (usually when the leader } \\
\text { has the appropriate skills), leaders will rise to the } \\
\text { challenge and are more likely to display TL }\end{array}$ & $\begin{array}{l}\text { Encourage leaders to take on challenging } \\
\text { yet positive responsibilities and to initiate } \\
\text { creative, positive changes }\end{array}$ \\
\hline - Span of control & $\begin{array}{l}\text { Negatively related to TL; if leaders have too many } \\
\text { team-members below them it will become too } \\
\text { difficult to provide each team-member individual } \\
\text { consideration }\end{array}$ & $\begin{array}{l}\text { - Reduce leaders' span of control to as small } \\
\text { a team as possible }\end{array}$ \\
\hline
\end{tabular}


Table 2. Training TL recommendations, including example content, and target skills and behaviors

\begin{tabular}{|c|c|}
\hline Training Recommendations & Example Content \\
\hline $\begin{array}{l}\text { 1. Gather information on leader and team-member perceptions } \\
\text { of leader's TL skills and behaviors }\end{array}$ & $\begin{array}{l}\text { Use the Multifactor Leadership Questionnaire (MLQ); have both } \\
\text { leaders and subordinates fill out questionnaire }\end{array}$ \\
\hline $\begin{array}{l}\text { 2. In a one-on-one with the leader, compare and contrast leader } \\
\text { perceptions and team-member perceptions }\end{array}$ & $\begin{array}{l}\text { As part of the comparison, have the leader answer questions such as: } \\
\text { "What differences do you see in ratings? Why do you think there are } \\
\text { these differences? Why do your team-members agree/disagree with } \\
\text { you?" [44] }\end{array}$ \\
\hline $\begin{array}{l}\text { 3. In same one-on-one, discuss strengths and weaknesses as well } \\
\text { as ways to maintain/enhance strengths and ways to improve } \\
\text { weaknesses }\end{array}$ & $\begin{array}{l}\text { As part of the discussion, ask questions such as: "What can you do to } \\
\text { address weakness \#? What are the specific steps you can take to } \\
\text { improve (relevant characteristics)?" }\end{array}$ \\
\hline $\begin{array}{l}\text { 4. Have leader develop an action plan to improve TL focused } \\
\text { skills and behaviors }\end{array}$ & $\begin{array}{l}\text { Using the MLQ, have the leader specify target behaviors and skills to } \\
\text { address over the course of a specific timeline (e.g., } 1 \text { month, } 3 \text { months, } \\
6 \text { months, etc.). }\end{array}$ \\
\hline $\begin{array}{l}\text { 5. Along with the action plan, set-up a group-based workshop } \\
\text { for all leaders in the organization to discuss TL strategies }\end{array}$ & $\begin{array}{l}\text { Leaders should discuss different strategies for incorporating TL skills } \\
\text { and behaviors, possible obstacles they may face, and ways to } \\
\text { overcome those obstacles. }\end{array}$ \\
\hline $\begin{array}{l}\text { 6. As part of the group workshop, set-up opportunities for } \\
\text { observational learning and role modeling }\end{array}$ & $\begin{array}{l}\text { Have a leader act out effective TL behaviors and skills as well as } \\
\text { ineffective behaviors and skills. Have a group discussion about what } \\
\text { went right and what went wrong then have the leaders in training act } \\
\text { out the behaviors and skills themselves. }\end{array}$ \\
\hline $\begin{array}{l}\text { 7. Ensure there is a plan in place to evaluate leaders' progress in } \\
\text { developing TL behaviors }\end{array}$ & $\begin{array}{l}\text { Evaluation plans can include leaders' own action plans, } \\
\text { re-assessments using the MLQ, and follower input on leader progress. }\end{array}$ \\
\hline Trainable TL Skills and Behaviors & Recommendations for Organizations \\
\hline $\begin{array}{l}\text { Strong sense of self that instills confidence in team } \\
\text { members/increased self-efficacy (Idealized Influence) }\end{array}$ & $\begin{array}{l}\text { Have leaders engage in guided self-reflective exercises. Provide } \\
\text { constructive \& consistent feedback in leader training so they know } \\
\text { where they are succeeding and improving. }\end{array}$ \\
\hline Increased emotional intelligence abilities (Idealized Influence) & $\begin{array}{l}\text { Train on how to identify personal and other's emotions accurately as } \\
\text { well as how to manage personal emotions so they do not interfere with } \\
\text { decision-making. Train on how to effectively react to and address } \\
\text { other's emotions. }\end{array}$ \\
\hline $\begin{array}{l}\text { Clearly communicate the vision and mission (goals) to } \\
\text { team-members (Inspirational Motivation) }\end{array}$ & $\begin{array}{l}\text { Develop a clear understanding of the vision/mission and then have } \\
\text { leaders practice communicating it in various formats (e.g., give the } \\
\text { elevator speech, write an email, website posting, etc.) }\end{array}$ \\
\hline $\begin{array}{l}\text { Passion for the organization and team's purpose (Inspirational } \\
\text { Motivation) }\end{array}$ & $\begin{array}{l}\text { Educate leaders on positive characteristics of the organization and the } \\
\text { successful contributions by the leader and his/her team }\end{array}$ \\
\hline $\begin{array}{l}\text { Constructive and individualistic feedback (Individualized } \\
\text { Consideration) }\end{array}$ & $\begin{array}{l}\text { Provide leader with resources to set-up one-on-ones with each } \\
\text { team-member to discuss individual development. Recognize and } \\
\text { celebrate individual and team accomplishments }\end{array}$ \\
\hline Other orientation and inclusion (Individualized Consideration) & $\begin{array}{l}\text { Have leaders get to know team members as individuals, their } \\
\text { strengths, and personal goals. Leverage those strengths for achieving } \\
\text { excellent outcomes. }\end{array}$ \\
\hline $\begin{array}{l}\text { Good listening skills and ability to effectively gather employee } \\
\text { input (Intellectual Stimulation) }\end{array}$ & $\begin{array}{l}\text { Train on active listening skills, considering others' ideas, entertaining } \\
\text { all contributions. Train leaders to guide through questioning rather } \\
\text { than telling }\end{array}$ \\
\hline
\end{tabular}

\section{TRAINing FOR TRANSFORMATIONAL LEADERSHIP}

While it is optimal for organizations to hire leaders who are naturally high in these personal characteristics, it is also possible to provide training to increase TL qualities in existing leadership staff. ${ }^{[14,25]}$ Training should follow the following steps: education about TL, application of content presented during education, personal goal setting for implementing TL behaviors, and follow-up meetings with facilitators and training evaluation. In Table 2, we provide more detail about training to increase TL characteristics

In a TL training intervention provided by Barling and associates, leaders participated in a one-day group training session. ${ }^{[39]}$ During this session, leaders were introduced to the core concepts of TL and its different dimensions. Next, trainees role-played use of TL behaviors in their own workplace. Afterward, trainees set goals in developing personal TL behaviors. Finally, each trainee had two individual followup booster sessions. During these sessions they discussed in their individualized plans to implement TL and the progress 
they had made. ${ }^{[14]}$ Results of this training indicated that subordinates of managers who completed the training reported a significant increase in their managers' TL behaviors compared to subordinates whose managers did not complete the training.

The Full Range Leadership Development program $\left(\right.$ FRLD $^{[25]}$ ) closely mirrors the steps of Barling and associates' training. First, leaders were introduced to the core concepts of TL through education. In lieu of role-modeling TL behaviors, the FRLD program next presented case studies to distinguish between TL and transactional leaders. Next, the leaders in the FRLD program set personal goals to incorporate the tenets of TL into their day to day leadership behaviors. Follow-up to this training indicated a sustained increase in trainees' TL behaviors and achievement of organizational goals at three months, six months, and two years later. ${ }^{[25]}$

Finally, there are specific individual characteristics associated with TL that can be increased through training. Specifically, trainable individual characteristics include self-efficacy and emotional intelligence. ${ }^{[40-43]}$

In Table 2 and below, we provide specific steps and recommendations on how to train TL, including how to increase self-efficacy and emotional intelligence through training. We also present additional specific skills that should be incorporated into TL-focused training.

\section{Training considerations for implementation of TL}

It is imperative to obtain both leader and follower perceptions of nurse leaders trainees' current level of TL using commonly accepted measures of TL such as the Multifactor Leadership Questionnaire. ${ }^{[4]}$ If notable discrepancies exist between their self-perceptions and what their followers report, those inconsistencies should be discussed candidly with nurse leader trainees. ${ }^{[44]}$

All training strategies must include developing a plan for personal implementation of TL behaviors. ${ }^{[45]}$ One-on-one meetings with nurse leader trainees (i.e., the nursing unit leader) should focus on the trainee's perceived weaknesses and strengths and strategies to improve behaviors in the appropriate areas. Specific skills including clear articulation of goals (Inspirational Motivation), inclusion of follower input and ideas into plans (Intellectual Stimulation), and strategies for providing personal attention to individual followers (Individualized Consideration) should be addressed in one-on-one training sessions. Alternately, group training sessions involving nurse leaders from all departments within the organization may be useful for skill development. ${ }^{[39]}$

Leaders' self-efficacy to successfully engage in TL behaviors 6 may be increased through consistent and constructive feedback. ${ }^{[41]}$ Likewise, emotional intelligence may be increased through self-awareness training focused on identifying one's own emotions as well as how one reacts to others. ${ }^{[43]}$ Once self-awareness has been established, training should focus on recognizing others' emotions and responding appropriately, and finally understanding the role of emotions within a team. ${ }^{[46]}$

\section{ORgANizATIONAL CHARACTERISTICS AND TL}

Environmental characteristics, including organizational structures and processes, can either promote or hinder TL behaviors among leaders. Two main areas emerge as organizational antecedents of TL: leader relations within the organization and organization-related demands and stressors. In addition to reviewing the literature below, we also summarize the impact of organizational characteristics on TL in Table 1 to accompany recommendations for organizations.

\subsection{Organizational demands}

Leaders' ability to engage in TL behaviors can be largely impacted by organizational demands placed upon them. It is crucial for health care organizations to remain aware of these demands and take steps to mitigate them to create an environment conducive to TL. Challenges such as implementing and adapting to change, managing a wide-breadth and high level of responsibility, and thriving under diversity, depend upon the nursing unit leader's expertise and are positively related to TL through leader engagement. ${ }^{[4]}$ Deep acting, the emotional labor demand extremely common in nursing which involves matching internal emotions with external behaviors, can also increase TL. ${ }^{[48]}$ Likewise, appropriate match or fit of leader abilities to organizational demands is a crucial predictor of TL. ${ }^{[49]}$ Leaders possessing the appropriate requisite knowledge, skills, and abilities for a position will be able to demonstrate competence required for the dimension of Idealized Influence.

Demands that can be matched with abilities and viewed as challenges to overcome empower leaders and are positive predictors of Idealized Influence, Inspirational Motivation, Individualized Consideration, and Intellectual Stimulation. However, unmanageable challenges can lead to leader exhaustion, decrease in self-efficacy, and consequently increased occurrence of laissez-faire leadership. ${ }^{[32,47]}$ It is important for healthcare organizations to remain aware of the demands placed on leaders and the impact of those demands can have on increasing or decreasing TL behaviors.

Nurse managers often report high levels of emotional exhaustion, precipitated by role conflict, quantitative workload, 
and other organizational characteristics. ${ }^{[50]}$ The number of employees under a leader's direct supervision, or span of control, can also impact the ability to provide the Individualized Consideration that is fundamental to TL. ${ }^{[30]}$ A large span of control is not necessarily a demand to overcome but one that constrains leaders from being able to develop relationships with nurses on their team, understand their goals, and leverage their strengths for enhanced team productivity. Thus, smaller teams under the direct supervision of nurse leaders can facilitate implementation of TL, and it is important for healthcare organizations to remain aware of the demands placed on leaders and the impact of those demands can have on increasing or decreasing TL behaviors.

\subsection{Leader relations}

Transformational leaders cultivate positive relationships with both superiors and subordinates. These relationships positively influence both leader and follower self-efficacy, while increasing motivation and organizational TL outcomes. ${ }^{[33]}$ Nurse leaders are likely to develop these positive work relationships when they identify with their healthcare organizations or unit as a collective, making a sense of group membership critical to leader relations. This collective identity is also perceived as more transformational in style by followers, ${ }^{[51]}$ reinforcing the importance of positive social relationships within the workplace in promoting TL.

\section{Conclusions}

We have presented a thorough discussion of personal characteristics associated with TL and organizational considerations for increasing TL through training and culture. Transformational leaders are high in extraversion, agreeableness, emotional stability, humility, self-efficacy, CSE, and Emotional Intelligence. These qualities allow them to positively connect with others on a personal level and engage followers through the four tenets of TL. Nurses working with transformational leaders can experience higher job satisfaction and improved personal wellness, decreased burnout and turnover rates. Patient care is also likely to improve when TL creates a culture in which nurses are not afraid to report errors or concerns. In turn, health care organizations save money through decreased staff turnover and improved patient care. Health care organizations aiming to improve TL either within specific nursing departments or throughout an entire institution should approach this effort as a full developmental plan that is directed from the top down. Successful implementation of TL requires an organization-wide culture that supports invoking change to reach ideal visions.

Specifically, we recommend that healthcare organizations consider the following steps to increase TL within their nurs- ing units and potentially other departments. These recommendations are also provided in Tables 1 and 2. First, healthcare organizations need to make TL characteristics a part of their selection process. That is, when selecting nursing leaders, either when hiring or promoting, it is important to select a nursing leader who is sociable (extraverted), agreeable, and humble. Additionally, it is important to ensure that nursing leaders feel confident in their abilities to be a transformational leader (i.e., have high self-efficacy) and have positive evaluations of themselves (i.e., are high in CSE; see Table 1). These individual characteristics can be improved in trainings by providing constructive feedback and identifying nursing leaders' successes. In addition to increasing nursing leaders' self-confidence, it is important to ensure that nursing leaders are high in emotional intelligence and perspective-taking. Again, these characteristics should be considered when selecting a nursing leader - however, these characteristics can be trained as well (see Table 2).

Second, healthcare organizations need to consider environmental characteristics that can either help or hinder TL within their units and consider making adjustments to these characteristics (see Table 1). Healthcare organizations should ensure that there are opportunities for nursing leaders to be transformational. For example, it is important to provide nuring leaders with the resources and support to initiate positive change within their unit. Additionally, nursing leaders need to be equipped with the abilities and resources to meet the demands of the position.

Beyond including TL traits as part of the selection process and providing appropriate opportunities for nursing leaders to be transformational, we recommend that healthcare organizations direct resources towards the development and implementation of a training program specifically designed to increase TL. While we understand that resources are scarce, significant resources are lost in critically high RN turnover. Recognizing the beneficial impact TL can have on RN retention, we believe the benefits of providing TL training outweigh the costs. To help initiate this effort, we have provided example training programs and content as well as recommendations for training in prior sections and Table 2. Overall, if each of these areas are aligned (selecting for TL characteristics, creating an environment where TL can thrive, and training TL skills and behaviors), healthcare organizations can noticeably increase TL within their nursing units and likely see a significant improvement in RN satisfaction and retention.

\section{CONFlicts of InTEREST Disclosure}

The authors declare they have no conflict of interest. 


\section{REFERENCES}

[1] 2015 National healthcare retention \& RN staffing report [Internet]. NSI Nursing Solutions, Inc.; 2015 [cited 2015 Mar 30]. Available from: http://www.nsinursingsolutions.com/files/asse ts/library/retention-institute/NationalHealthcareR NRetentionReport2015.pdf

[2] Brewer CS, Kovner CT, Obeidat RF, et al. Positive work environments of early-career registered nurses and the correlation with physician verbal abuse. Nurs. Outlook. 2013; 61: 408-416. PMid: 23489412. https://doi.org/10.1016/j.outlook.2013.01.004

[3] Hayes B, Bonner A, Pryor J. Factors contributing to nurse job satisfaction in the acute hospital setting: a review of recent literature. J. Nurs. Manag. 2010; 18: 804-814. PMid: 20946216. https://doi.org/10.1111/j.1365-2834.2010.01131.x

[4] Cho E, Sloane DM, Eun-Young Kim, et al. Effects of nurse staffing, work environments, and education on patient mortality: An observational study. Int. J. Nurs. Stud. 2015; 52: 535-542. PMid: 25213091. https://doi.org/10.1016/j.ijnurstu. 2014.08.006

[5] Dahinten VS, Lee SE, MacPhee M. Disentangling the relationships between staff nurses' workplace empowerment and job satisfaction. J. Nurs. Manag. [Internet]. 2016. Available from: http://ezproxy.umsl.edu/login?url=http: //search. ebscohost. com/login. aspx?direct $=$ true\&db=cm edm\&AN $=27353065 \&$ site $=$ ehost - live\&s cope $=$ site

[6] Brewer CS, Kovner CT, Djukic M, et al. Impact of transformational leadership on nurse work outcomes. J. Adv. Nurs. [Internet]. 2016 Available from: http://ezproxy.umsl.edu/login?url=http: $/ /$ search.ebscohost. com/login. aspx?direct $=$ true $\& d b=c m$ edm\&AN $=27346330 \&$ site $=$ ehost - live\&s cope=site

[7] Moseley A, Jeffers L, Paterson J. The retention of the older nursing workforce: A literature review exploring factors which influence the retention and turnover of older nurses. Contemp. Nurse J. Aust. Nurs. Prof. 2008; 30: 46-56. https://doi .org/10.5172/conu.673.3 0.1 .46

[8] Hoch JE, Bommer WH, Dulebohn JH, et al. Do ethical, authentic, and servant leadership explain variance above and beyond transformational leadership? A meta-analysis. J. Manag. [Internet]. 2016 [cited 2017 Mar 1]. Available from: http://journals.sagepub .com/doi/pdf/10.1177/0149206316665461

[9] Judge TA, Piccolo RF. Transformational and Transactional Leadership: A Meta-Analytic Test of Their Relative Validity. J. Appl. Psychol. 2004; 89: 755-768. PMid: 15506858. https://doi.org/ 10.1037/0021-9010.89.5.755

[10] AbuAlRub RF, Alghamdi MG. The impact of leadership styles on nurses' satisfaction and intention to stay among Saudi nurses. J. Nurs. Manag. 2012; 20: 668-678. PMid: 22823223. https: //doi.org/10.1111/j.1365-2834.2011.01320.x

[11] Malloy T, Penprase B. Nursing leadership style and psychosocial work environment. J. Nurs. Manag. 2010; 18: 715-725. PMid: 20840366. https://doi.org/10.1111/j.1365-2834.2010.0 1094. $\mathrm{x}$

[12] Martin J. Personal relationships and professional results: The positive impact of transformational leaders on academic librarians. J. Acad. Librariansh. 2017; 43: 108-115. https://doi.org/10.1016/j. acalib.2017.01.012

[13] Berkovich I, Eyal O. The mediating role of principals' transformational leadership behaviors in promoting teachers' emotional wellness at work. Educ. Manag. Adm. Leadersh. 2017; 45: 316-335. https://doi.org/10.1177/1741143215617947

[14] Barling J, Slater F, Kelloway EK. transformational leadership and emtional intelligence: an exploratory study. Leadersh. Organ. Dev. J.
2000; 21: 157-161. https://doi.org/10.1108/014377300103 25040

[15] Choi SL, Goh CF, Adam MBH, et al. Transformational leadership, empowerment, and job satisfaction: the mediating role of employee empowerment. Hum. Resour. Health. 2016; 14: 1-14. PMid: 27903294. https://doi.org/10.1186/s12960-016-0171-2

[16] Diebig M, Bormann KC, Rowold J. Day-level transformational leadership and followers' daily level of stress: a moderated mediation model of team cooperation, role conflict, and type of communication. Eur. J. Work Organ. Psychol. 2017; 26: 234-249. https://doi.org/10.1080/1359432X.2016.1250741

[17] Hentrich S, Zimber A, Garbade SF, et al. Relationships between transformational leadership and health: The mediating role of perceived job demands and occupational self-efficacy. Int. J. Stress Manag. 2017; 24: 34-61. https://doi.org/10.1037/str0000027

[18] Morsiani G, Bagnasco A, Sasso L. How staff nurses perceive the impact of nurse managers' leadership style in terms of job satisfaction: a mixed method study. J. Nurs. Manag. [Internet]. 2016. Available from: http://ezproxy.umsl.edu/login?url=http: //search.ebscohost. com/login. aspx?direct=true\&db=cm edm\&AN $=27917561 \&$ site $=$ ehost $-l$ ive\&s $c o p e=$ site

[19] Ariyabuddhiphongs V, Kahn SI. Transformational leadership and turnover intention: The mediating effects of trust and job performance on café employees in Thailand. J. Hum. Resour. Hosp. Tour. 2017; 16: 215-233. https ://doi.org/10.1080/15332845.201 6.1202730

[20] Cowden TL, Cummings GG. Testing a theoretical model of clinical nurses' intent to stay. Health Care Manage. Rev. 2015; 40: 169181. PMid: 24566247. https://doi.org/10.1097/HMR.000000 0000000008

[21] Weng RH, Huang CY, Chen LM, et al. Exploring the impact of transformational leadership on nurse innovation behaviour: a crosssectional study. J. Nurs. Manag. 2015; 23: 427-439. PMid: 24033847. https://doi.org/10.1111/jonm.12149

[22] Wong CA, Cummings GG, Ducharme L. The relationship between nursing leadership and patient outcomes: a systematic review update. J. Nurs. Manag. 2013; 21: 709-724. PMid: 23865924. https : //doi.org/10.1111/jonm.12116

[23] Caillier JG, Sa Y. Do transformational-oriented leadership and transactional-oriented leadership have an impact on whistle-blowing attitudes? A longitudinal examination conducted in US federal agencies. Public Manag. Rev. 2017; 19: 406-422. https://doi.org/ 10.1080/14719037.2016.1177109

[24] Hillen H, Pfaff H, Hammer A. The association between transformational leadership in German hospitals and the frequency of events reported as perceived by medical directors. J. Risk Res. 2017; 20: 499515. https://doi.org/10.1080/13669877.2015.1074935

[25] Bass BM. Two decades of research and development in transformational leadership. Eur. J. Work Organ. Psychol. 1999; 8: 9-32. https://doi.org/10.1080/135943299398410

[26] Fischer SA. Transformational leadership in nursing: a concept analysis. J. Adv. Nurs. 2016; 72: 2644-2653. PMid: 27322510. https://doi.org/10.1111/jan.13049

[27] Marshall ES. Transformational leadership in nursing: From expert clinician to influential leader. New York, NY: Springer Publishing Co., LLC; 2011.

[28] Oswald FL, Hough LM. Personality and its assessment in organizations: Theoretical and empirical developments. In: Zedeck S, Zedeck S (Ed), editors. APA Handb. Ind. Organ. Psychol. Vol 2 Sel. Dev. Memb. Organ. [Internet]. Washington, DC, US: American Psychological Association; 2011. 153-184 p. Available from: http://ezproxy.umsl.edu/login?url=http: 
//search. ebscohost. com/login. aspx?direct=true\&db=ps yh\&AN $=2010-06018-005 \&$ site $=$ ehost - live\&s cope=site

[29] Bono JE, Judge TA. Personality and transformational and transactional leadership: a meta-analysis. J. Appl. Psychol. 2004; 89: 901910. PMid: 15506869. https://doi.org/10.1037/0021-9010. 89.5.901

[30] Rubin RS, Munz DC, Bommer WH. Leading from within: The effects of emotion recognition and personality on transformational leadership behavior. Acad. Manage. J. 2005; 48: 845-858. https : //doi.org/10.5465/AMJ .2005.18803926

[31] Nielsen R, Marrone JA, Slay HS. A new look at humility: Exploring the humility concept and its role in socialized charismatic leadership. J. Leadersh. Organ. Stud. 2010; 17: 33-43. https: //doi.org/10.1177/1548051809350892

[32] Fitzgerald S, Schutte NS. Increasing transformational leadership through enhancing self-efficacy. J. Manag. Dev. 2010; 29: 495-505. https ://doi.org/10.1108/02621711011039240

[33] Trépanier SG, Fernet C, Austin S. Social and motivational antecedents of perceptions of transformational leadership: A selfdetermination theory perspective. Can. J. Behav. Sci. Rev. Can. Sci. Comport. 2012; 44: 272-277. https : //doi .org/10.1037/a002 8699

[34] Bandura A. Self-efficacy: The exercise of self-control. 1st ed. New York, NY: W.H. Freeman and Company; 1997.

[35] Hu J, Wang Z, Liden RC, et al. The influence of leader core selfevaluation on follower reports of transformational leadership. Leadersh. Q. 2012; 23: 860-868. https://doi.org/10.1016/j.leaq ua. 2012.05.004

[36] Mayer JD, Roberts RD, Barsade SG. Human Abilities: Emotional Intelligence. Annu. Rev. Psychol. 2008; 59: 507-536. PMid: 17937602. https://doi.org/10.1146/annurev.psych.59.1 03006.093646

[37] Leban W, Zulauf C. Linking emotional intelligence abilities and transformational leadership styles. Leadersh. Organ. Dev. J. 2004; 25: 554-564. https://doi.org/10.1108/01437730410561440

[38] Gregory BT, Moates KN, Gregory ST. An exploration of perspective taking as an antecedent of transformational leadership behavior. Leadersh. Organ. Dev. J. 2011; 32: 807-816. https://doi.org/ 10.1108/01437731111183748

[39] Barling J, Weber T, Kelloway EK. Effects of transformational leadership training on attitudinal and financial outcomes: A field experiment. J. Appl. Psychol. 1996; 81: 827-832. https ://doi .org/10 .1037/0021-9010.81.6.827
[40] Cherniss C, Adler M. Promoting emotional intelligence in organization: Make training in emotional intelligence effective. Alexandria, VA: American Society for Training and Development; 2000.

[41] Gist ME, Mitchell TR. Self-efficacy: A theoretical analysis of its determinants and malleability. Acad. Manage. Rev. 1992; 17: 183-211.

[42] Parle M, Maguire P, Heaven C. The development of a training model to improve health professionals' skills, self-efficacy and outcome expectancies when communicating with cancer patients. Soc. Sci. Med. 1997; 44: 231-240. https ://doi.org/10.1016/S0277-9 536 (96) 00148-7

[43] Slaski M, Cartwright S. Emotional intelligence training and its implications for stress, health and performance. Stress Health J. Int. Soc. Investig. Stress. 2003; 19: 233. https ://doi.org/10.1002/smi. 979

[44] Bass BM. From transactional to transformational leadership: Learning to share the vision. 1990.

[45] Warrick DD. The urgent need for skilled transformational leaders: Integrating transformational leadership and organization development. J. Leadersh. Account. Ethics. 2011; 8: 11-26.

[46] Brackett MA, Katulak NA. Emotional Intelligence in the Classroom: Skill-Based Training for Teachers and Students. In: Ciarrochi J, Mayer JD, Ciarrochi J (Ed), et al., editors. Appl. Emot. Intell. Pract. Guide [Internet]. New York, NY, US: Psychology Press; 2007. 1-27 p. Available from: http://ezproxy.umsl.edu/login?url=http: //search.ebscohost. com/login. aspx?direct=true\&db=ps yh\&AN=2007-01312-001\&s ite=ehost -1 ive\&s cope=site

[47] Courtright SH, Colbert AE, Choi D. Fired up or burned out? How developmental challenge differentially impacts leader behavior. J. Appl. Psychol. 2014; 99: 681-696. PMid: 24490967. https: //doi.org/10.1037/a0035790

[48] Barnes CM, Guarana CL, Nauman S, et al. Too tired to inspire or be inspired: Sleep deprivation and charismatic leadership. J. Appl. Psychol. 2016; 101: 1191-1199. PMid: 27159583. https : //doi.org/10.1037/apl0000123

[49] Guay RP. The relationship between leader fit and transformational leadership. J. Manag. Psychol. 2013; 28: 55-73. https : //doi.or g/10.1108/02683941311298869

[50] Van Bogaert P, Adriaenssens J, Dilles T, et al. Impact of role-, joband organizational characteristics on Nursing Unit Managers' work related stress and well-being. J. Adv. Nurs. 2014; 70: 2622-2633. PMid: 24842679. https ://doi.org/10.1111/jan.12449

[51] Johnson RE, Venus M, Lanaj K, et al. Leader identity as an antecedent of the frequency and consistency of transformational, consideration, and abusive leadership behaviors. J. Appl. Psychol. 2012; 97: 12621272. PMid: 22730903. https://doi.org/10.1037/a0029043 